\title{
Filamentous bacteria existence in aerobic granular reactors
}

\author{
M. Figueroa, A. Val del Río, J. L. Campos, R. Méndez and A. Mosquera-Corral*,
}

Department of Chemical Engineering, Institute of Technology, University of Santiago de Compostela, 15782 Santiago de Compostela, Galicia, Spain. Tel.: +34 881816739; fax: +34 881816702. e-mail: monica.figueroa@usc.es; mangeles.val@usc.es; joseluis.campos@usc.es; ramon.mendez.pampin@usc.es; anuska.mosquera@usc.es.

*Corresponding author: anuska.mosquera@usc.es

\begin{abstract}
Filamentous bacteria are associated to biomass settling problems in wastewater treatment plants. In systems based on aerobic granular biomass they have been proposed to contribute to the initial biomass aggregation process. However their development on mature aerobic granular systems has not been sufficiently studied. In the present research work filamentous bacteria were studied for the first time after long term operation (up to 300 days) of aerobic granular systems. Chloroflexi and Sphaerotilus natans have been observed in a reactor fed with synthetic wastewater. These filamentous bacteria could only come from the inoculated sludge. Thiothrix and Chloroflexi bacteria were observed in aerobic granular biomass treating wastewater from a fish canning industry. Meganema perideroedes was detected in a reactor treating wastewater from a plant processing marine products. As a conclusion the source of filamentous bacteria in these mature aerobic granular systems fed with industrial effluents was the incoming wastewater.
\end{abstract}

Keywords: aerobic granulation; Chloroflexi; industrial wastewater; Meganema perideroedes; Sphaerotilus natans; Thiothrix.

\section{INTRODUCTION}

Aerobic granulation is a microbial self-immobilization process that is driven by diverse selection pressures such as the applied organic loading rate and hydrodynamic shear forces, the presence of a feastfamine regime, the feeding strategy, the reactor configuration, the cycle time distribution or the volume exchange ratio [1]. It is a gradual process, involving progression from flocs to granular aggregates [2]. Aerobic granules are characterized by regular outer shapes and compact structures [2], and are mainly composed of microbial populations and extracellular polymeric substances [3]. Unfavourable conditions like: wastewater composition, low substrate availability, dissolved oxygen deficiency, long solids retention time, nutrient deficiency and high temperature promote filamentous outgrowth [4,5]. It has been stated that low-levels of filamentous growth do not cause operational problems and may even stabilize the granule structure [4]. Zhang et al. [6] observed that filamentous bacteria appeared to initiate granule formation and generate the structures that supported further granule growth. However, in the case of 
filamentous overgrowth, the settleability of the aerobic granules becomes poor. Biomass washout and eventual disappearance of aerobic granules can subsequently occur [4].

Filamentous bacteria are normally present in the activated sludge in small amounts. Under specific conditions they proliferate to such an extent that they markedly affect the treatment plant performance causing sludge bulking or foaming. In order to control the growth of these problematic bacteria, their identification has been required. More than 30 different filamentous bacterial morphotypes have been described based on their morphology $[7,8]$.

Nowadays, the identification based on morphotypes is known to be frequently inadequate for the reliable identification of many filamentous bacteria, since one morphotype can embrace several phylogenetically very different organisms [9]. For example, previous studies have revealed that the Nostocoida limicola morphotypes are affiliated to members as diverse as the phyla Chloroflexi, Firmicutes, and Actinobacteria, the class Alphaproteobacteria and the order Planctomycetales. Molecular techniques have allowed resolving the taxonomic affiliations of some of these bacteria [10,11]. The use of fluorescence in situ hybridization (FISH) with rRNA-targeted oligonucleotides has been dedicated to their identification.

Different research works proposed several strategies to avoid or mitigate the presence of filamentous organisms in aerobic granular sludge. Wan et al. [12] studied the effect of $\mathrm{pH}$ in aerobic granular systems fed with synthetic media. These authors proposed to impose alkaline conditions inside the reactor as an effective way to suppress filamentous overgrowth and maintain granule stability, although in this study the tested operational time was only of 14 days. Weissbrodt et al. [13] proposed the application of intensive up-flow aeration and/or the use of sludge from a biological nutrient removal system as inoculum. These authors operated five different aerobic granular reactors along 40-50 days fed with synthetic media. They explained that the application of high shear forces helped to break the superficial filamentous structures, while the sludge from the biological nutrient removal process exhibits a lower filamentous bulking potential than the sludge from organic matter removal process. From existing studies it is inferred that there is lack of research works where filamentous bacteria are studied operated with industrial wastewater in long term operation experiments.

The present work is focused on the study of the reasons for filamentous growth in aerobic granular systems fed with industrial wastewater and synthetic media simulating a previous physical-chemical treatment, in long-term experiments (between 120 and 400 days). The observations made at laboratory scale, with industrial wastewater at long operational times, are expected to help to understand the possible problems in the operation of the industrial full scale plants.

\section{MATERIALS AND METHODS}

\section{Reactors operation}

Three sequencing batch reactors (SBRs), R1, R2 and R3, were operated to obtain aerobic granular sludge from the inoculated activated sludge. The SBRs were operated in cycles of 3 hours with short settling and effluent withdrawal periods to generate wash-out conditions in order to select for granulation in the reactors [14]. The cycle distribution was chosen with the aim to obtain the granulation process and the 
organic matter removal, not optimized for nutrients removal. Each reactor was fed with a different type of wastewater, namely a synthetic wastewater with coagulant-flocculant reagents (R1) and two industrial effluents from fish cannery (R2) and marine products processing (R3) plants (Table 2). The operation of the three SBRs took place at the laboratories of the University of Santiago de Compostela. The industrial wastewaters were collected once a month and stored at $4{ }^{\circ} \mathrm{C}$ in the university installations prior to be fed to the SBRs. The process of granules formation and the time needed to obtain stable granules and their properties were different in each system, according to the special features of each feeding composition. The details about the operation could be consulted in Val del Río et al. [15] for R1, Figueroa et al. [16] for R2 and Val del Río et al. [17] for R3.

Samples of granular biomass to perform the FISH analysis were collected from the reactors on different operational days. Among them, in this study, those samples corresponding to periods when filamentous bacteria were observed are analysed. Samples were collected from R1 on days 84 and 115; from R2 on days 268 and 344 and from R3 on days 192 and 263. Furthermore samples of control (without presence of filamentous bacteria) were taken on day 99 for R2 and day 94 for R3.

\section{Synthetic medium plus coagulant-flocculant (R1)}

R1 was fed with a synthetic solution containing sodium acetate as carbon source and supplemented with residual quantities of coagulant $(2.5 \mathrm{mg} / \mathrm{L}$ of aluminium polychloride) and flocculant $(1.5 \mathrm{mg} / \mathrm{L} \mathrm{of}$ polyelectrolyte) in the range of concentrations normally applied to the primary settled wastewater. R1 was run in parallel under the same operational conditions as the control reactor $(\mathrm{RC})$. RC was only fed with the synthetic medium without addition of coagulant-flocculant reagents and only served for comparison with R1.

$\mathrm{R} 1$ and RC were inoculated with $0.5 \mathrm{~L}$ of activated sludge collected from an activated sludge system for organic matter and nitrogen removal, located in an urban wastewater treatment plant (WWTP). The sludge volume index (SVI) was of $200 \mathrm{~mL} / \mathrm{g}$ TSS and the solids concentration of $5 \mathrm{~g}$ VSS/L. Granules were already observed in R1 and RC on day 10 of operation. In the case of RC most of them were smaller than $2 \mathrm{~mm}$ while in R1 they were larger than $2 \mathrm{~mm}$ (see supplementary data Figure 1S). The SVI decreased from 180 to $40 \mathrm{~mL} / \mathrm{g}$ TSS in RC while this parameter remained between 80 and $100 \mathrm{~mL} / \mathrm{g}$ TSS in the case of R1. The rapid formation of these aggregates with such a high SVI could be related to the presence of the coagulant and flocculant reagents contained in the feeding media that promoted the aggregation of the biomass but hindered its compactness. The outgrowth of filamentous structures on the surface of the granules of R1 on day 116 could be observed on Figure 1SD.

R1 was operated during 120 days with high COD removal efficiencies during the whole operational time (Figure 1S). Nitrogen removal was performed from day 40 of operation on mainly via nitrificationdenitrification. On days 84 and 115, when the biomass samples were taken, the organic matter and nitrogen removal efficiencies were around $95 \%$ and $60 \%$, respectively.

\section{Fish cannery wastewater (R2)}

R2 was fed with the effluent produced in a fish canning industry (Pontevedra, Spain) containing high and low salts content. The feeding used from days 1 to 149 contained over $9 \mathrm{~g} \mathrm{NaCl} / \mathrm{L}$ and after this date the concentration decreased to $0.1 \mathrm{~g} \mathrm{NaCl} / \mathrm{L}$, due to a modification of the industrial process. 
The sludge used as inoculum was $0.5 \mathrm{~L}$ of a flocculent activated sludge from a unit for organic matter and nitrogen removal, located in an urban WWTP (different than R1 and RC), with a SVI of $100 \mathrm{~mL} / \mathrm{g}$ TSS. In this reactor the formation of the aerobic granules was observed on day 45. During the whole operational period filamentous outgrowth on the surface of the granules was observed under the stereomicroscope (see supplementary data Figure 2S).

R2 was operated during 400 days and the operational strategy consisted of a stepwise increase of organic matter and nitrogen concentrations (Figures 2SA and 2SB). Organic matter removal efficiencies were of $93 \%, 91 \%$ and $95 \%$ on days 99,268 and 344 , while nitrogen removal efficiencies were of $25 \%, 31 \%$ and $26 \%$, respectively, achieved mainly via nitrification-denitrification. The sample taken on day 99 corresponded to a period of high saline conditions $(9 \mathrm{~g} \mathrm{NaCl} / \mathrm{L})$ and samples from days 268 and 344 to low saline conditions $(0.1 \mathrm{~g} \mathrm{NaCl} / \mathrm{L})$.

\section{Marine products processing wastewater (R3)}

R3 was fed with the wastewater from a plant processing marine products (A Coruña, Spain) characterized by a wide variability of its composition in terms of organic matter (from 380 to $3,800 \mathrm{~g} \mathrm{COD} / \mathrm{L}$ ) and nitrogen (from 370 to $2,250 \mathrm{mg} \mathrm{NH}_{4}{ }^{+}-\mathrm{N} / \mathrm{L}$ ) content.

$\mathrm{R} 3$ was inoculated with $0.5 \mathrm{~L}$ of activated sludge from the biological reactor (for organic matter removal) operated in the site of the seafood industry, characterized by a SVI of $125 \mathrm{~mL} / \mathrm{g}$ TSS and a solids concentration of $3.2 \mathrm{~g}$ VSS/L. Aggregates with a large diameter were quickly developed in 30 days from the start up. A high growth in size of the existent granules was observed reaching values of the mean feret diameter as high as $11 \mathrm{~mm}$. Different breakup episodes and new granulation events occurred through the whole operational period [17] (see supplementary data Figure 3S).

High COD removal efficiencies were obtained during most part of the operational time, except for the period between days 98 and 108; however, nitrogen removal efficiency was low (Figure 3S). Organic matter and nitrogen removal efficiencies were of $73 \%$ and $0 \%$ on day $94,93 \%$ and $12 \%$ on day 192 , and $93 \%$ and $14 \%$ on day 263 , respectively.

\section{Analytical methods}

The size distribution and morphology of the granules were determined regularly by using an image analysis procedure [18] with a stereomicroscope (Stemi 2000-C, Zeiss) and by scanning electron microscopy (SEM) (Digital SEM 440, Leica). For SEM analysis the sludge samples were washed with phosphate buffer (PBS) and fixed, with a solution of glutaraldehyde 3\% (v/v) in PBS, overnight. After fixation the sample was dehydrated using ethanol solutions with increasing ethanol concentrations ( 30 , $50,70$ and $100 \%$ in $\mathrm{v} / \mathrm{v})$.

The FISH technique was applied to disaggregated biomass samples. To achieve the granular biomass breakage, samples were sonicated for $1 \mathrm{~min}$ at $65 \%(135 \mu \mathrm{m})$ of amplitude using a probe sonicator (UP200s, Dr. Hielscher). These conditions were selected to only de-aggregate the granules without breaking the cells. FISH was performed according to the procedure described by Amann et al. [19]. Biomass samples were initially fixed in paraformaldehyde $4 \%(\mathrm{~m} / \mathrm{v})$ for 2 hours. Then they were immobilized on microscope slides and dried by successive passage through ethanol at $50 \%, 80 \%$ and $98 \%$ $(\mathrm{v} / \mathrm{v})$. Later the hybridization with the selected probes was performed at $46{ }^{\circ} \mathrm{C}$ for 1.5 hours. Used probes 
are listed in Table 1S (supplementary information) and details are available at probeBase [20]. The criteria used for the selection of the FISH probes was the identification of filamentous bacteria, based on Nielsen et al. [9], according to Table 1. The main populations targeted by FISH were Meganema perideroedes, Sphaerotilus natans and Chloroflexi. The oligonucleotide probes were labelled with the fluorochromes $\mathrm{Cy} 3$ and FITC. After in situ hybridization slides were washed with buffer solution, dried and embedded with Vectashield H-1200 containing DAPI (4',6-DiAmidino-2-Phenylindole) stain supplied by Atom S.A. (Barcelona). Fluorescence signals were recorded with an acquisition system coupled to an epifluorescence microscope (Axioskop 2, Zeiss). The wavelengths for probe excitation were 495, 558 and $359 \mathrm{~nm}$, while for fluorescence detection were 519, 670 and $461 \mathrm{~nm}$, for FITC, Cy3 and DAPI, respectively.

\section{RESULTS}

A two-step FISH approach was used for the detection of filamentous populations present in the biomass samples. The general FISH probes for the Proteobacteria classes were applied first. Later more specific ones providing positive signal at genus level were applied for deeper insights into these general groups. All the probes tested in this work are presented in the supplementary data (Table 1S). The probes that did not provide positive signal are also listed in this table, but are not further mentioned in the following discussion.

\section{R1: Synthetic medium plus coagulant-flocculant}

Filamentous bacteria were observed during the visualization of the biomass samples collected from RC on day 114 and from R1 on days 84 and 115, and analyzed with probe EUB338 $8_{\text {mix }}$. In case of R1 positive results were obtained only with probe Bet42a for Betaproteobacteria. After testing the specific probes available for each one of the filamentous organisms (Table 1S) of this class, positive results were only obtained after the application of probe SNA for Sphaerotilus natans (Figure 1A). Their abundance in the sample was high and the characteristics of the observed filaments corresponded to those reported for the S. natans morphotype (straight or bent sheathed filaments), that in the present case rarely exceeded the 25 $\mu \mathrm{m}$ long. The comparison between samples from days 84 and 115 indicates that the abundance of filamentous bacteria in both operating days was similar.

A remainder fraction of filamentous bacteria in R1 was identified after the application of probe CFX1223 as Chloroflexi. The filaments of Chloroflexi bacteria had a length between 15 and $25 \mu \mathrm{m}$ and their abundance in this reactor was significant as shown in Figure 1B.

S. natans bacteria were found to be present in the inoculum used for RC and R1, although the percentage in the inoculum was much lower than that observed on day 115 of operation of R1 (Figure 1A). Furthermore in spite of the use of the same inoculum, neither S. natans nor Chloroflexi were observed in the sample collected from RC on day 114 .

The main difference in the operation of the two reactors relied on the presence of coagulant and flocculant in the feeding media of R1. These differences in the observations made at microbial level therefore suggest an effect of these compounds on microbial selection. The coagulants are normally positively charged and they are designed to neutralize the repulsive electrical charges (typically negative) 
surrounding particles. Their presence favours the creation of flocs, while the flocculants facilitate the agglomeration or aggregation of the coagulated particles to form larger floccules. The addition of both reagents could facilitate the retention of filamentous bacteria in the system, and the posterior operational conditions led to their development.

\section{R2: Fish cannery}

The sample collected on day 99 of operation was used as reference sample and showed the absence of filamentous bacteria in the biomass at that operational stage of the reactor. However filamentous bacteria were observed in the samples collected on days 268 and 344 after the application of EUB338 $8_{\text {mix }}$ probe. Positive results after application of the general probes were detected with Gammaproteobacteria, probe Gam42a (Figure 2A). Specific probes to detect microorganisms of this class were applied (Table 1S). The filamentous bacteria of the sample were identified to belong to genus Thiothrix with the probe G123T (Figure 2B). Filamentous bacteria that belonged to phylum Chloroflexi were also identified, and positive hybridizations were obtained after the use of probes CFX1223 (Figure 2D) and GNSB941.

With regards to abundance in the sample from day 344, the length of Chloroflexi bacteria was around 30 $\mu \mathrm{m}$, shorter than the observed length of the Thiothrix filamentous, that ranged from 75 to $300 \mu \mathrm{m}$ (Figure 2B), and their abundance was also to a lesser extent (Figure 2D).

Images obtained with the SEM technique on day 374 (Figure 2C) showed the filamentous microorganisms tightly wrapped and connected surrounding the non-filamentous bacteria and also growing on the surface of the granules. In this case it seems that the filamentous bacteria could act as a structural backbone of the aerobic granules.

The filamentous bacteria detected by FISH on days 268 and 344 apparently did not cause operational problems such as bulking or bad setteability of the biomass. The SVI was indeed low during the different operational periods (56 and $79 \mathrm{~mL} / \mathrm{g}$ TSS, respectively). However, the excessive growth of Thiothrix could be responsible of the breakage of the granules observed after day 355 of operation. In the case of Chloroflexi, due to the low and constant abundance of these filamentous bacteria in the analyzed samples, it can be stated that their presence in this reactor was not relevant for the breakage event of the granular biomass.

\section{R3: Processing marine products}

In the case of the samples collected on days 192 and 263 from R3 after applying the probes listed on Table 1S, two different morphotypes of filamentous organisms were observed.

The biggest filaments resembled fungal hyphae (Figure 3A), and this was corroborated by the positive signals obtained once probes EUK516 and MY1574 were applied.

The second type of observed filaments were curved bacteria that presented positive fluorescent signal with probe Alflb (Figure 3B). From the application of the probes available for the identification of Alphaproteobacteria filamentous species (Table 1S) positive results were obtained after the use of probes MEG983 and MEG1028 ( MEG $_{\text {mix }}$ ) for Meganema perideroedes (Figure 3C). Moreover, by the use of the FISH technique the observation of the septa that form the structure of these type of filamentous bacteria, and also their high abundance in the sample, was possible (Figure 3D). 
The amount of eukaryotic cells detected on days 192 and 263 was similar and an increase in the abundance of Meganema was observed between days 192 and 263. This excessive growth of Meganema in the granules could be related to the increase of the average feret diameter of the granules and their further breakage.

When the reference sample taken on day 94 was analyzed, only few fungal hyphae were observed and Meganema bacteria were not detected.

\section{DISCUSSION}

The major goal of this work was the study of filamentous bacteria proliferation in mature aerobic granular systems fed with industrial wastewater and synthetic media simulating a previous physical-chemical treatment. The effects of the presence of these microorganisms on the aerobic granules seem not as important as it usually is on the performance of activated sludge systems. To clarify the factors responsible for their development in the aerobic granules can provide relevant information to understand their stability and performance.

To identify the conditions for the growth of filamentous bacteria two different kinds of factors were analysed: on the one hand the inoculum and the incoming wastewater as the source of microbial populations; on the second hand the operational conditions such as nutrients or dissolved oxygen limitations and so on.

\section{Inoculum and wastewater composition}

As RC and R1 were fed with a synthetic media the origin of the filamentous organisms, detected in both reactors, was attributed to the inoculum. In these reactors Sphaerotilus natans and Chloroflexi were present in relative high abundance in the analyzed samples.

Filamentous bacteria such as Sphaerotilus were believed for many years to be the main causative organism of bulking in activated sludge systems [7]. Sphaerotilus are obligate aerobic organisms, able to consume a wide variety of carbon sources, organic acids, sugars, alcohols and amino acids [11]. In the line of the present study Weissbrodt et al. [13] also observed the presence of Sphaerotilus in aerobic granular system inoculated with activated sludge and fed also with a synthetic media containing acetate as carbon and energy source.

Filamentous members of the phylum Chloroflexi have occasionally been associated to bulking incidences in activated sludge systems, although no particular industrial waste was found to favour their presence. They were detected in wastewater treatment systems from different industries as well as in activated sludge systems in municipal WWTPs [21,22] and also in autotrophic nitrifying granules [23]. In the present study they appear almost in constant amounts in the reactors fed with synthetic media and fish cannery wastewater.

Thiothrix and Meganema bacteria were only detected in R2 and R3, respectively, which were fed with industrial wastewater. These bacteria were not observed in the first operational stages of both reactors operation (reference samples: day 99 for R2 and 94 for R3).

Thiothrix is a filamentous sulfur bacteria belonging to the class Gammaproteobacteria, that was also found to cause settleability problems in activated sludge processes and loss of solids from secondary 
clarifiers [24]. The reason for the absence of Thiothrix and also Cholroflexi in the granules from R2 (sample day 99) might be the presence of high sodium chloride concentrations. Their further development means that the source of origin could be the incoming wastewater once the saline conditions moved to low concentrations. Furthermore it is known that the presence of suspended organic compounds or other slowly biodegradable substrates in the industrial wastewater (not present in a synthetic medium) favoured the growth of filamentous structures at the surface of aerobic granules [25].

Filamentous Alphaproteobacteria, such as Meganema, were abundant and often involved in bulking and possibly foaming episodes in activated sludge processes. They were present in about $65 \%$ of 86 industrial WWTPs investigated in former studies [26] but their broad distribution would suggest that none of the filamentous Alphaproteobacteria was preferentially associated to a plant treating a particular industrial waste [26]. However in the present case they seem to come with the treated effluent. Physiological characteristics of $M$. perideroedes were reported by Kragelund et al. [27] and among other characteristics, these bacteria are obligate aerobic, oxidase and catalase-positive, consume acetate and glucose under aerobic conditions and seem to have an unusually high substrate uptake capability.

Several studies on fungi and protozoa in activated sludge systems demonstrated that these eukaryotic organisms fulfil different tasks in wastewater systems, related to sludge dewaterability and toxic resistance, COD removal, nitrification or denitrification activities [28,29]. However in the present study they were only present when the fish processing wastewater was fed indicating their possible presence in the inoculum or in this kind of effluent.

It is clear that the effects of these two factors (inoculum and type of wastewater) are not enough to explain the abundance of these organisms in aerobic granular biomass where the operation is designed to select for non-filamentous bacteria. It is clear that the operational conditions of each system promoted the establishment and further development of filamentous bacteria which seem to be almost ubiquitous in all granular systems.

For this reason, in order to explain the presence of filamentous bacteria, some of the hypotheses valid for the case of activated sludge formulated to find a general solution to the associated problems of biomass floatation can be considered also in the case of aerobic granules [10].

\section{Effects of operational conditions}

In order to analyze the operation of the three reactors, according to the different possible factors affecting the development of filamentous organisms, information regarding reactors operation and physical properties of the biomass is presented in Table 3 .

An initial explanation is based on the diffusion based theory which relates the excessive growth of filamentous microorganisms to substrate diffusional resistance inside biological flocs in case of activated sludge [30]. This phenomenon has also been recently related to the presence of suspended solids or colloidal substrates in the feeding [25] and the way for filamentous bacteria to reach substrates. This could be explained by the fact that under non-bulking process conditions, filamentous bacteria could still be present inside the floc and if substrate limitation occurs they will then quickly grow out of it. This might be the case, for example, of Sphaerotilus which were present in the inoculum of RC and R1. These microorganisms are known to appear occasionally in plants with nutrient deficiency $[11,31]$. 
This theory would explain the presence of filamentous organism in the surface of the aerobic granules due to oxygen limiting conditions which has been found frequently in this kind of systems [5] when high organic loads are treated. Furthermore with granular structures the substrate is consumed locally, enhancing substrate gradients inside the granules and thus stimulating the outgrowth of filamentous structures [25]. In the present study, more specifically in R1 the growth of filamentous organisms on the granules surface occurred on day 65 and lasted until the end of the reactor operation (Figure 1SD). In the case of R2 and R3 these filamentous structures were also observed under the stereomicroscope (Figures $2 \mathrm{SD}$ and $3 \mathrm{SD})$.

In order to relate these observations to the physical properties of the biomass the value of the average diameter of the granules could be considered as an influencing factor. Due to this the biggest the granule the highest the difficulty of the substrates, specially dissolved oxygen to penetrate the biomass. The average feret diameter increases due to the increase of the treated OLR up to values close to $2.5-3.0 \mathrm{~kg}$ $\mathrm{COD} /\left(\mathrm{m}^{3} \cdot \mathrm{d}\right)$. In R1 and R2 the feret diameter increased in the last collected sample up to values of 4.9 and $5.8 \mathrm{~mm}$, respectively. In the case of R3, although a feret diameter of $2.4 \mathrm{~mm}$ was measured on day 192 , it reached a value of $11.0 \mathrm{~mm}$ on day 226 , when the granules broke up. Therefore, a high OLR and feret diameter could hinder the dissolved oxygen transfer from the bulk liquid to the inner zones of the granules and promote the growth of filamentous bacteria and the breakage of the granules. This was also observed by authors like Zheng et al. [32], who obtained the formation of large granules with filamentous surface when the applied OLR was as high as $6 \mathrm{~kg} \mathrm{COD} /\left(\mathrm{m}^{3} \cdot \mathrm{d}\right)$, and then, due to mass transfer limitation, the disintegration of the granules occurred.

A second explanation relies on the kinetic selection theory which states that in systems where the substrate concentration experiences periods of high substrate concentration, like in plug-flow reactors or SBR systems, the filamentous bacteria should be suppressed since their growth rate is expected to be lower than that for floc forming bacteria [33]. In this way the alternation of feast and famine (presence and absence of organic substrate in the liquid media) conditions is used to promote the formation of aerobic granules selecting for microorganisms which tend to aggregate [34]. To impose alternating feast and famine conditions allows for the development of bacteria which are able to rapidly store the organic matter as glycogen, lipids or Poly- $\beta$-hidroxyalkanoates (PHA). This ability presumably provides an extra advantage to non-filamentous bacteria in dynamic systems, while the growth of filamentous bacteria is avoided. In this sense a short feast phase is preferable to avoid filamentous outgrowth [35]. However for $\mathrm{R} 1$ the feast phase was longer than in RC, which promoted the growth of filamentous organism in the granules surface, while in RC this was not observed [15].

Certain filamentous organisms, such as Sphaerotilus are able to assimilate relatively high concentrations of substrates from which it synthesizes considerable amounts of poly- $\beta$-hydroxybutyrate and polysaccharides. The synthesis of both reserve compounds is stimulated by a high carbon/nitrogen ratio in the medium or by oxygen deficiency [36]. Also M. perideroedes cells contain PHA inclusions and have an extremely high substrate uptake rate and storage capacity, which is probably comparable to or higher than most floc-forming bacteria. In this case the filamentous morphology gives the organisms an ecological advantage. This ability could be especially advantageous under the feast-famine regimes [10] 
encountered for example in the aerobic granular SBRs. This could be one of the reasons for the predominance of $S$. natans in R1 and $M$. perideroedes in R3.

Another organism like Thiothrix was identified in systems treating different municipal and industrial wastewaters with and without nutrient removal [31]. Wastewaters rich in reduced sulphur compounds, nutrients deficiency or in systems operated with low feeding to microorganisms $(\mathrm{F} / \mathrm{M})$ ratios are environments where Thiothrix is commonly found [7,37]. These bacteria are capable to store sulphur granules and PHA; and have rapid nutrients uptake rates under nutrient deficiency. The outgrowth of these bacteria in aerobic granules cultivated with brewery wastewater has been previously reported [38] and they were thought to be responsible of the bulking and settling problems, probably caused by the high applied OLR $\left(3.6 \mathrm{~kg} \mathrm{COD} /\left(\mathrm{m}^{3} \mathrm{~d}\right)\right)$, the dissolved oxygen deficiency or the high temperatures of operation reported in that research. In the present research the presence of Thiothrix was observed in the reactor treating fish canning effluent with large salts content.

In order to evaluate the effect of the feed to microorganisms $(\mathrm{F} / \mathrm{M})$ ratio the solids concentration inside the reactors was measured. Its value was of $2.5 \mathrm{~g} \mathrm{VSS} / \mathrm{L}$ in $\mathrm{R} 1$ while it was over $6 \mathrm{~g} \mathrm{VSS} / \mathrm{L}$ in R2 and R3. As a result the fed OLR and the values of the F/M ratio were different in each reactor. R1 was operated under relatively high $\mathrm{F} / \mathrm{M}$ ratio (around $1 \mathrm{~kg} \mathrm{COD} /(\mathrm{kg} \mathrm{VSS} \cdot \mathrm{d})$ ), and this was reported as one of the possible factors that caused the growth of S. Natans [9]. However, R2 and R3 were operated at lower F/M values that are favorable for the growth of most of the filamentous species [8,32]. The increase of the F/M ratio in these reactors between the two last selected operating days (Table 3) could favour the development of Thiothrix and Meganema species.

The presence of fungi has been observed in systems with aerobic granules as it is the case of R3. Recent studies indicate that fungal hyphae also act like skeletal elements in the structural formation process $[29,38]$. Weber et al. [38] observed that filamentous fungal pellets dominated the sludge population in the first 10 to 15 days and they served to initiate the granular biofilm structure as an immobilizing matrix for bacteria. These authors checked that these fungi were still present in mature granules, where they supported the development and maintenance of the granular structure.

Other possible causes of the outgrowth of filamentous bacteria in aerobic granular sludge SBRs are related to long solids retention time (SRT) values, high substrate gradients within the granule, flow patterns or temperature shifts [4]. Therefore, because of the cyclic operation of aerobic granular sludge SBR and peculiarities of aerobic granules, several of these conditions can be present simultaneously and they can result in progressive development of filamentous growth in aerobic granular sludge SBR.

\section{Conclusions}

Filamentous bacteria were detected in all the aerobic granular systems studied, which corroborates that they form part of the granular structure. The results of the present study suggested that the biomass used as inoculum and the type of wastewater treated correlated with the presence of filamentous bacteria detected in aerobic granular sludge. Sphaerotilus Natants were detected only in R1 fed with synthetic media where the feeding to microorganisms ration was around $1 \mathrm{~kg} \mathrm{COD} /(\mathrm{kg} \mathrm{VSS} \cdot \mathrm{d})$.

In the case of the aerobic granular system fed with synthetic wastewater the source of filamentous bacteria is attributed to the inoculum. This means that the filamentous organisms were not completely 
washed from the system in the initial granulation stage but they remain and develop if the operational conditions are appropriated.

In the case of mature aerobic granular systems fed with industrial wastewater the source of filamentous bacteria was presumably the fed substrate. This means that the filamentous organisms present in the feeding predominate instead of the inoculated ones.

The appearance of filamentous outgrowth in the surface of the granules corresponded with the application of high OLRs, which provoked the increase of granules diameter. The high diameter of the granules hindered the transfer of dissolved oxygen from the bulk liquid to the center of the granules. The oxygen limitation promoted the growth of filamentous bacteria.

\section{ACKNOWLEDGEMENTS}

This work was funded by the Spanish Government through NOVEDAR Consolider (CSD2007-00055) and PLASTICWATER (CTQ2011-22675) projects. The authors belong to the Galician Competitive Research Group GRC 2013-032, programme co-funded by FEDER. 
Table 1. Overview of the phylogenetic affiliation, species name (if possible) and corresponding morphotype (adapted from Nielsen et al. [9]).

\begin{tabular}{|c|c|c|}
\hline \multicolumn{3}{|l|}{ Phylum/class } \\
\hline \multirow{4}{*}{$\begin{array}{l}\text { Proteobacteria/ } \\
\text { Alphaproteobacteria }\end{array}$} & Candidatus Alysiosphaera europea, C. Monilibacter & \\
\hline & batavus, $C$. Alysiomicrobium bavaricum and $C$. & Nostocoida limicola \\
\hline & Combothrix itálica & \\
\hline & Meganema perideroedes & Type $021 \mathrm{~N}$ \\
\hline \multirow{4}{*}{$\begin{array}{l}\text { Proteobacteria/ } \\
\text { Betaproteobacteria }\end{array}$} & Genus Curvibacter & Type 1701 \\
\hline & Genus Curvibacter & Type 0041/0675 \\
\hline & Sphaerotilus natans & Sphaerotilus natans \\
\hline & Leptothrix discophora & Leptothrix \\
\hline \multirow{5}{*}{$\begin{array}{l}\text { Proteobacteria/ } \\
\text { Gammaproteobacteria }\end{array}$} & Thiothrix nivea, T. unzii, T. fructosivorans, T. defluvii & Thiothrix species \\
\hline & T. eikelboomii, T. disciformis, T. flexilis & Type $021 \mathrm{~N}$ species \\
\hline & Acinetobacter spp. & Type 1863 \\
\hline & Leucothrix mucor & Leucothrix mucor \\
\hline & Beggiatoa spp. & Beggiatoa \\
\hline \multirow{4}{*}{ Bacteroidetes } & Haliscomenobacter hydrossis & H. hydrossis \\
\hline & Other $H$. hydrossis-like species & H. hydrossis-like \\
\hline & Unknown species & Type 0092 \\
\hline & Chryseobacterium spp. & Type 1863 \\
\hline \multirow{5}{*}{ Chloroflexi } & Kouleothrix aurantiaca & Type 1851 \\
\hline & Unknown species & N. limicola II \\
\hline & Other Chloroflexi, (species not identified) & $\begin{array}{l}\text { H. hydrossis-like (- } \\
\text { epiphytic growth) }\end{array}$ \\
\hline & Other Chloroflexi, (species not identified) & $\begin{array}{l}\text { Type } 1851 \text { (+ epiphytic } \\
\text { growth) }\end{array}$ \\
\hline & Other Chloroflexi, (species not identified) & $\begin{array}{l}\text { Type 0041/0675 ( } \\
\text { epiphytic growth) }\end{array}$ \\
\hline
\end{tabular}


Table 2. Operational parameters of the aerobic granular SBRs

\begin{tabular}{|c|c|c|c|}
\hline & $\mathrm{R} 1$ & $\mathrm{R} 2$ & R3 \\
\hline Type of feeding & Synthetic & Fish cannery & $\begin{array}{c}\text { Processing marine } \\
\text { products }\end{array}$ \\
\hline Peculiarity & $\begin{array}{l}\text { Coagulant- } \\
\text { flocculant reagents }\end{array}$ & $\begin{array}{c}\text { Variable salt } \\
\text { concentration }(9 \text { and } \\
0.1 \mathrm{~g} \mathrm{NaCl} / \mathrm{L})\end{array}$ & Variable composition \\
\hline $\mathrm{COD}_{\mathrm{T}}\left(\mathrm{mg} \mathrm{O}_{2} / \mathrm{L}\right)^{\mathrm{b}}$ & - & $390-1,130$ & $380-3,800$ \\
\hline $\mathrm{COD}_{\mathrm{S}}\left(\mathrm{mg} \mathrm{O}_{2} / \mathrm{L}\right)^{\mathrm{c}}$ & $550-850$ & $270-1,020$ & $370-2,250$ \\
\hline $\mathrm{NH}_{4}^{+}\left(\mathrm{mg} \mathrm{NH}{ }^{+}-\mathrm{N} / \mathrm{L}\right)$ & $55-85$ & $36-190$ & $45-370$ \\
\hline TSS (mg/L) & - & $15-200$ & $30-224$ \\
\hline $\operatorname{VSS}(\mathrm{mg} / \mathrm{L})$ & - & $5-80$ & $30-190$ \\
\hline $\mathrm{pH}$ & $6.9-7.6$ & $6.6-7.7$ & $6.5-7.1$ \\
\hline
\end{tabular}

${ }^{\mathrm{b}} \mathrm{CO} \mathrm{D}_{\mathrm{T}}$ : total chemical oxygen demand.

${ }^{\mathrm{c}} \mathrm{COD}_{\mathrm{s}}$ : soluble chemical oxygen demand. 
Table 3. Operational conditions of reactors and physical properties of aerobic granular sludge at the days of biomass sampling.

\begin{tabular}{|c|c|c|c|c|c|c|c|c|c|}
\hline Reactor & & $\mathrm{R} 1$ & & & $\overline{\mathrm{R} 2}$ & & & R3 & \\
\hline$\overline{\text { Day }}$ & Inoculum & 84 & 115 & 99 & 268 & 344 & 94 & 192 & 263 \\
\hline $\begin{array}{l}\mathrm{OLR}_{\text {treated }} \\
\left(\mathrm{kg} \mathrm{COD}_{\mathrm{s}} /\left(\mathrm{m}^{3} \mathrm{~d}\right)\right)\end{array}$ & - & 2.55 & 2.51 & 1.4 & 2.10 & 3.11 & 3.4 & 2.10 & 2.94 \\
\hline $\begin{array}{l}\mathrm{NLR}_{\text {treated }} \\
\left(\mathrm{kg} \mathrm{N} /\left(\mathrm{m}^{3} \mathrm{~d}\right)\right)\end{array}$ & - & 0.17 & 0.19 & 0.05 & 0.12 & 0.09 & 0 & 0.02 & 0.07 \\
\hline SRT (d) & - & 5 & 5 & 62 & 51 & 10 & 2 & 14 & 5 \\
\hline $\operatorname{VSS}_{\text {reactor }}(\mathrm{g} / \mathrm{L})$ & 5 & 2.0 & 2.7 & 4.4 & 6.7 & 7.3 & 1.9 & 10.8 & 6.5 \\
\hline SVI (mL/g TSS) & 200 & 116.6 & 74.1 & 45.5 & 56.5 & 79.5 & 123.7 & 39.5 & 55.4 \\
\hline
\end{tabular}

n.d.: not determined due to the breakage

Abundance estimation: (-) negative, average number of filaments in 10 pictures taken at 400x: + , (less than 10$),++(10-35),+++($ more than 35$)$. 

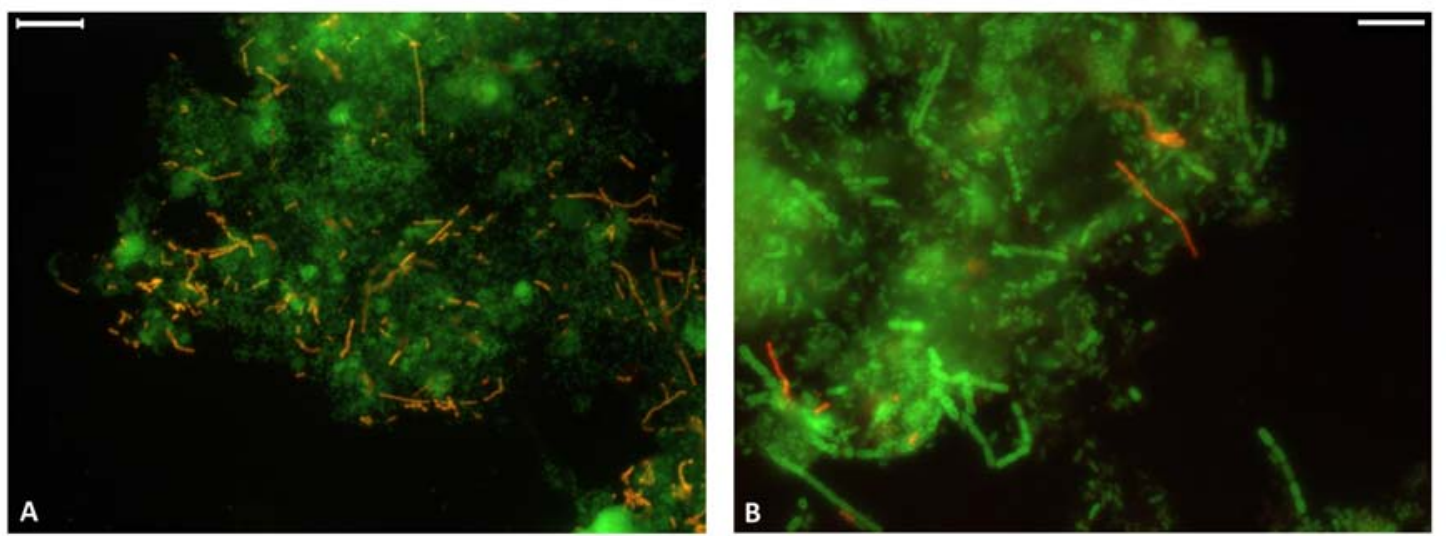

Figure 1. FISH images of filamentous bacteria from R1 on day 115. A) Probe SNA for Sphaerotilus Natans (Cy3) and probe EUB338 $8_{\text {mix }}$ for Bacteria (FITC). The bar indicates $25 \mu \mathrm{m}$. B) Probe CFX1223 for Chloroflexi (Cy3) and EUB338 $8_{\text {mix }}$ for Bacteria (FITC). The scale bar indicates $10 \mu \mathrm{m}$. 



Figure 2. FISH images of filamentous bacteria from R2 on day 344. A) Probe Gam42a for Gammaproteobacteria (Cy3) and DAPI. B) probe EUB338 $8_{\text {mix }}$ for Bacteria (FITC) and probe G123T for Thiothrix (Cy3). C) SEM image of a granule sampled on day 374 of operation. D) probe CFX1223 for Chloroflexi (Cy3) and probe EUB338 ${ }_{\text {mix }}$ for Bacteria (FITC). The scale bar indicates $25 \mu \mathrm{m}$ in A) and B), $20 \mu \mathrm{m}$ in $\mathrm{C}$ ) and $10 \mu \mathrm{m}$ in $\mathrm{D})$. 

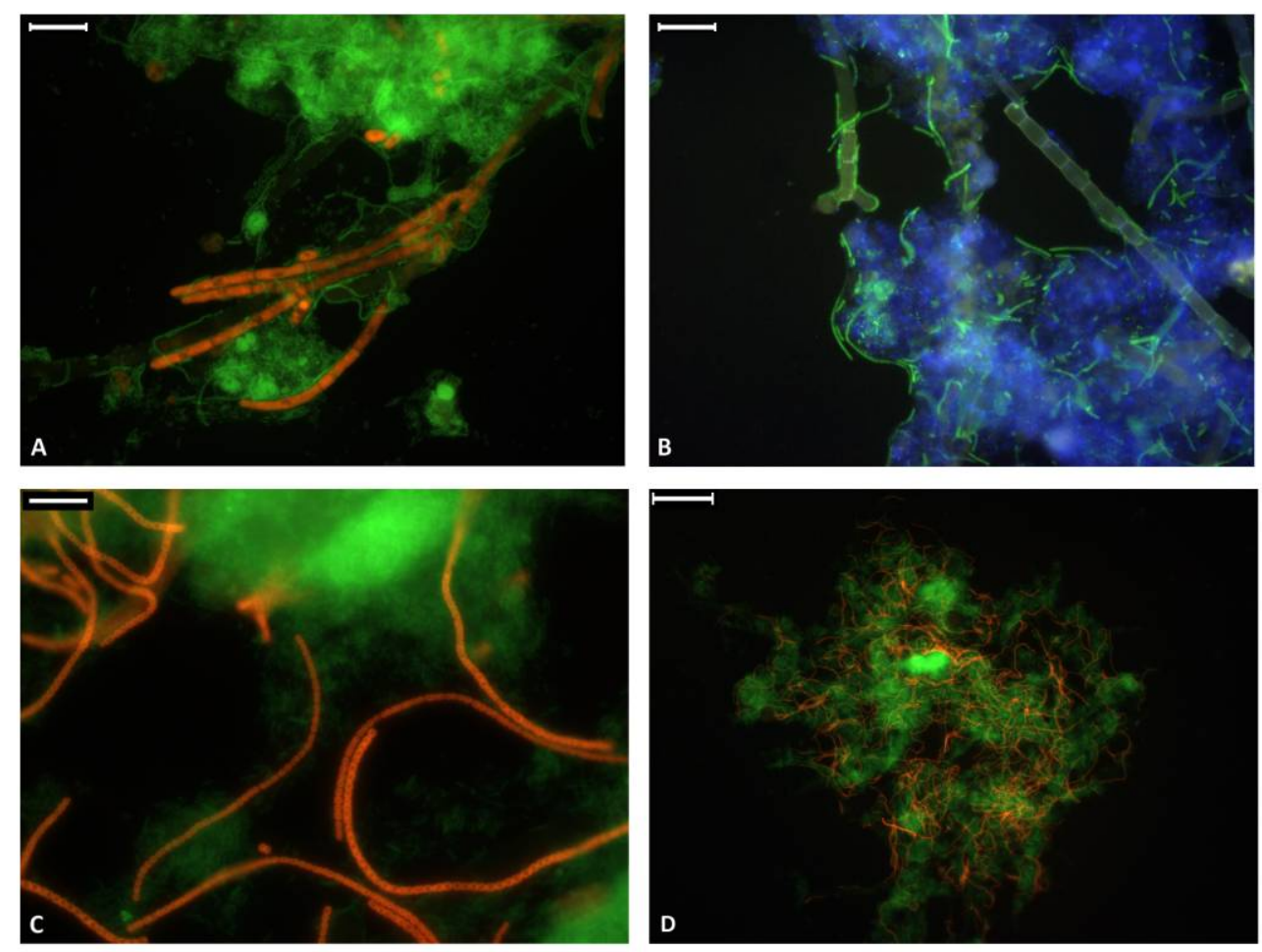

Figure 3. FISH images of filamentous organisms from R3 on day 263. A) probe EUK516 for Eukarya (Cy3) and probe EUB338 $8_{\text {mix }}$ for Bacteria (FITC). B) probe Alf1b for Alphaproteobacteria (FITC) and DAPI. C) and D) probe $\mathrm{MEG}_{\text {mix }}$ for Meganema (Cy3) and EUB338 $8_{\text {mix }}$ for Bacteria (FITC). The scale bar indicates $25 \mu \mathrm{m}$ in $\mathrm{A}$ ) and B), $10 \mu \mathrm{m}$ in C) and $100 \mu \mathrm{m}$ in D). 


\section{REFERENCES}

1. Qin L, Tay J-H, Liu Y (2004) Selection pressure is a driving force of aerobic granulation in sequencing batch reactors. Process Biochemistry 39 (5):579-584. doi:10.1016/s0032-9592(03)00125-0

2. Tay JH, Liu QS, Liu Y (2001) Microscopic observation of aerobic granulation in sequential aerobic sludge blanket reactor. Journal of Applied Microbiology 91 (1):168-175. doi:10.1046/j.13652672.2001.01374.x

3. McSwain BS, Irvine RL, Hausner M, Wilderer PA (2005) Composition and Distribution of Extracellular Polymeric Substances in Aerobic Flocs and Granular Sludge. Applied and Environmental Microbiology 71 (2):1051-1057. doi:10.1128/aem.71.2.1051-1057.2005

4. Liu Y, Liu Q-S (2006) Causes and control of filamentous growth in aerobic granular sludge sequencing batch reactors. Biotechnology Advances 24 (1):115-127. doi:10.1016/j.biotechadv.2005.08.001

5. Mosquera-Corral A, de Kreuk MK, Heijnen JJ, van Loosdrecht MCM (2005) Effects of oxygen concentration on N-removal in an aerobic granular sludge reactor. Water Research 39 (12):2676-2686. doi:10.1016/j.watres.2005.04.065

6. Zhang B, Ji M, Qiu Z, Liu H, Wang J, Li J (2011) Microbial population dynamics during sludge granulation in an anaerobic-aerobic biological phosphorus removal system. Bioresource Technology 102 (3):2474-2480. doi:http://dx.doi.org/10.1016/j.biortech.2010.11.017

7. Eikelboom DH (2000) Process control of activated sludge plants by microscopic investigation. IWA Publishing, London

8. Jenkins D, Richard MG, Daigger GT (2003) Manual on the causes and control of activated sludge bulking, foaming, and other solids separation problems. IWA Publishing, London

9. Nielsen H, Daims H, Lemmer H (2009) FISH handbook for biological wastewater treatment. IWA Publishing, London

10. Martins AMP, Pagilla K, Heijnen JJ, van Loosdrecht MCM (2004) Filamentous bulking sludge-a critical review. Water Research 38 (4):793-817. doi:http://dx.doi.org/10.1016/j.watres.2003.11.005

11. Nielsen PH, Kragelund C, Seviour RJ, Nielsen JL (2009) Identity and ecophysiology of filamentous bacteria in activated sludge. FEMS Microbiology Reviews 33 (6):969-998. doi:10.1111/j.15746976.2009.00186.x

12. Wan C, Yang X, Lee D-J, Zhang Q, Li J, Liu X (2014) Formation of filamentous aerobic granules: role of $\mathrm{pH}$ and mechanism. Applied Microbiology and Biotechnology 98 (19):8389-8397. doi:10.1007/s00253-014-5857-6

13. Weissbrodt DG, Lochmatter S, Ebrahimi S, Rossi P, Maillard J, Holliger C (2012) Bacterial selection during the formation of early-stage aerobic granules in wastewater treatment systems operated under wash-out dynamics. Frontiers in Microbiology 3. doi:10.3389/fmicb.2012.00332

14. Arrojo B, Mosquera-Corral A, Garrido JM, Méndez R (2004) Aerobic granulation with industrial wastewater in sequencing batch reactors. Water Research 38 (14-15):3389-3399. doi:10.1016/j.watres.2004.05.002

15. Val del Río A, Morales N, Figueroa M, Mosquera-Corral A, Campos JL, Mendez R (2012) Effect of Coagulant-Flocculant Reagents on Aerobic Granular Biomass. Journal of Chemical Technology \& Biotechnology 87 (7):908-913

16. Figueroa M, Mosquera-Corral A, Campos JL, Mendez R (2008) Treatment of saline wastewater in SBR aerobic granular reactors. Water Science and Technology 58 (2):479-485. doi:10.2166/wst.2008.406

17. Val del Rio A, Figueroa M, Mosquera-Corral A, Campos JL, Mendez R (2013) Stability of Aerobic Granular Biomass Treating the Effluent from A Seafood Industry. International Journal of Environmental Research 7 (2):265-276

18. Tijhuis L, Vanloosdrecht MCM, Heijnen JJ (1994) Formation and growth of heterotrophic aerobic biofilms on small suspended particles in airlift reactors. Biotechnology and Bioengineering 44 (5):595608 
19. Amann RI, Binder BJ, Olson RJ, Chisholm SW, Devereux R, Stahl DA (1990) Combination of 16S ribosomal-RNA-targeted oligonucleotide probes with flow-cytometry for analyzing mixed microbial populations. Applied and Environmental Microbiology 56 (6):1919-1925

20. Loy A, Maixner F, Wagner M, Horn M (2007) probeBase-an online resource for rRNA-targeted oligonucleotide probes: new features 2007. Nucleic Acids Research 35 (suppl 1):D800-D804. doi:10.1093/nar/gk1856

21. Bjornsson L, Hugenholtz P, Tyson GW, Blackall LL (2002) Filamentous Chloroflexi (green nonsulfur bacteria) are abundant in wastewater treatment processes with biological nutrient removal. Microbiology-Sgm 148:2309-2318

22. Kragelund C, Levantesi C, Borger A, Thelen K, Eikelboom D, Tandoi V, Kong Y, Van Der Waarde J, Krooneman J, Rossetti S, Thomsen TR, Nielsen PH (2007) Identity, abundance and ecophysiology of filamentous Chloroflexi species present in activated sludge treatment plants. FEMS Microbiology Ecology 59 (3):671-682. doi:10.1111/j.1574-6941.2006.00251.x

23. Matsumoto S, Katoku M, Saeki G, Terada A, Aoi Y, Tsuneda S, Picioreanu C, Van Loosdrecht MCM (2010) Microbial community structure in autotrophic nitrifying granules characterized by experimental and simulation analyses. Environmental Microbiology 12 (1):192-206. doi:10.1111/j.14622920.2009.02060.x

24. Williams TM, Unz RF (1985) Filamentous sulfur bacteria of activated sludge: characterization of Thiothrix, Beggiatoa, and Eikelboom type 021N strains. Applied and Environmental Microbiology 49 (4):887-898

25. de Kreuk MK, Kishida N, Tsuneda S, van Loosdrecht MCM (2010) Behavior of polymeric substrates in an aerobic granular sludge system. Water Research 44 (20):5929-5938. doi:10.1016/j.watres.2010.07.033

26. Levantesi C, Beimfohr C, Geurkink B, Rossetti S, Thelen K, Krooneman J, Snaidr J, van der Waarde J, Tandoi V (2004) Filamentous Alphaproteobacteria Associated with Bulking in Industrial Wastewater Treatment Plants. Systematic and Applied Microbiology $27 \quad$ (6):716-727. doi:http://dx.doi.org/10.1078/0723202042369974

27. Kragelund C, Nielsen JL, Thomsen TR, Nielsen PH (2005) Ecophysiology of the filamentous Alphaproteobacterium Meganema perideroedes in activated sludge. FEMS Microbiology Ecology 54 (1):111-112. doi:10.1016/j.femsec.2005.03.002

28. Nicolau A, Dias N, Mota M, Lima N (2001) Trends in the use of protozoa in the assessment of wastewater treatment. Research in Microbiology 152 (7):621-630. doi:http://dx.doi.org/10.1016/S09232508(01)01241-4

29. Weber SD, Hofmann A, Pilhofer M, Wanner G, Agerer R, Ludwig W, Schleifer K-H, Fried J (2009) The diversity of fungi in aerobic sewage granules assessed by $18 \mathrm{~S}$ rRNA gene and ITS sequence analyses. FEMS Microbiology Ecology 68 (2):246-254. doi:10.1111/j.1574-6941.2009.00660.x

30. Kappeler J, Gujer W (1994) Development of a mathematical model for "aerobic bulking". Water Research 28 (2):303-310. doi:http://dx.doi.org/10.1016/0043-1354(94)90268-2

31. van der Waarde J, Krooneman J, Geurkink B, van der Werf A, Eikelboom D, Beimfohr C, Snaidr J, Levantesi C, Tandoi V (2002) Molecular monitoring of bulking sludge in industrial wastewater treatment plants. Water Science and Technology 46 (1-2):551-558

32. Zheng Y-M, Yu H-Q, Liu S-J, Liu X-Z (2006) Formation and instability of aerobic granules under high organic loading conditions. Chemosphere 63 (10):1791-1800. doi:10.1016/j.chemosphere.2005.08.055

33. Chudoba J, Grau P, Ottová V (1973) Control of activated-sludge filamentous bulking-II. Selection of microorganisms by means of a selector. Water Research 7 (10):1389-1406. doi:10.1016/00431354(73)90113-9

34. McSwain BS, Irvine RL, Wilderer PA (2004) Effect of intermittent feeding on aerobic granule structure. Water Science and Technology 49 (11-12):19-25

35. de Kreuk MK, van Loosdrecht MCM (2004) Selection of slow growing organisms as a means for improving aerobic granular sludge stability. Water Science and Technology 49 (11-12):9-17 
36. Spring S (2006) The genera Lepthothrix and Sphaerotilus. In: Dworkin M, Falkow S, Rosenberg E, Schleifer KH, Stackebrandt E (eds) The Prokaryotes: Ecophysiology and Biochemistry. Springer, New York,

37. Nielsen PH, De Muro MA, Nielsen JL (2000) Studies on the in situ physiology of Thiothrix spp. present in activated sludge. Environmental Microbiology 2 (4):389-398. doi:10.1046/j.14622920.2000.00120.x

38. Weber SD, Ludwig W, Schleifer K-H, Fried J (2007) Microbial Composition and Structure of Aerobic Granular Sewage Biofilms. Applied and Environmental Microbiology 73 (19):6233-6240. doi:10.1128/aem.01002-07 


\section{Suplementary data}

Figure 1S
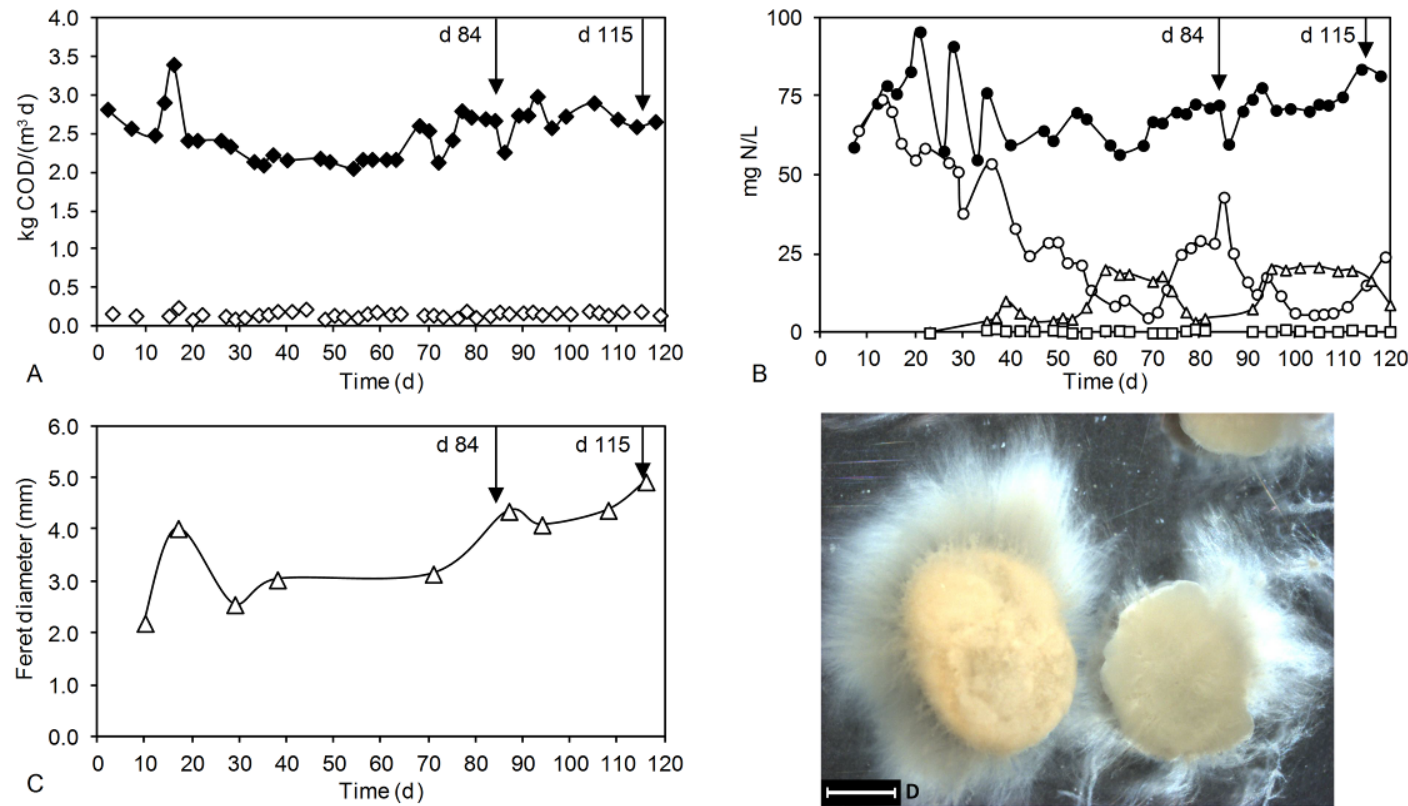

Figure 1S. Operational performance of R1 fed with synthetic medium plus coagulant-flocculant and sampling dates (days 84 and 115) indicated with arrows. A) Organic loading rate $\left(\mathrm{kg} \mathrm{COD} /\left(\mathrm{m}^{3} \mathrm{~d}\right)\right)$ in the influent $\left(\mathrm{OLR}_{\mathrm{inf}}, \diamond\right)$ and in the effluent $\left(\mathrm{OLR}_{\mathrm{eff}}, \diamond\right)$; B) nitrogen compounds concentrations (mg N/L): $\mathrm{NH}_{4}{ }^{+}-\mathrm{N}_{\text {inf }}(\bullet), \mathrm{NH}_{4}{ }^{+}-\mathrm{N}_{\text {eff }}(\bigcirc), \mathrm{NO}_{2}{ }^{-}-\mathrm{N}_{\text {eff }}(\triangle)$ and $\mathrm{NO}_{3}{ }^{-}-\mathrm{N}_{\text {eff }}(\square)$ in the reactor. C) Evolution of the feret diameter $(\mathrm{mm})$. D) Stereomicroscopy image of the granules on day 116 with the scale bar indicating 2 $\mathrm{mm}$. 
Figure $2 \mathrm{~S}$
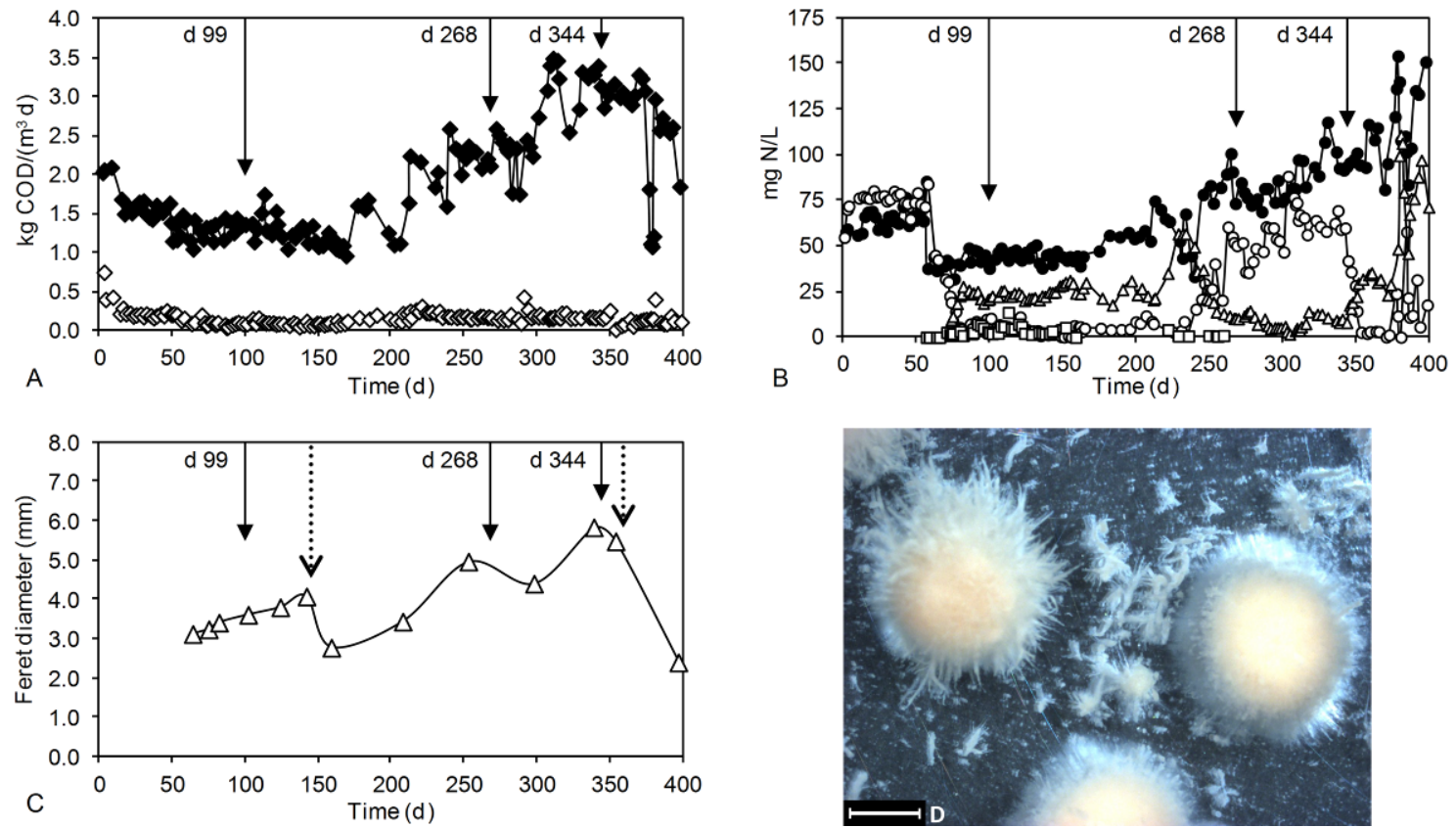

Figure 2S. Operational performance of R2 fed with fish cannery effluent and sampling dates (days 99, 268 and 344) indicated with arrows. A) Organic loading rate $\left(\mathrm{kg} \mathrm{COD} /\left(\mathrm{m}^{3} \mathrm{~d}\right)\right)$ in the influet $\left(\mathrm{OLR}_{\text {inf }}\right.$, and in the effluent $\left(\mathrm{OLR}_{\text {eff }}, \diamond\right)$ and B) nitrogen compounds concentrations $(\mathrm{mg} \mathrm{N} / \mathrm{L}): \mathrm{NH}_{4}{ }^{+}-\mathrm{N}_{\text {inf }}(\bullet)$, $\mathrm{NH}_{4}{ }^{+}-\mathrm{N}_{\text {eff }}(\bigcirc), \mathrm{NO}_{2}{ }^{-}-\mathrm{N}_{\text {eff }}(\triangle)$ and $\mathrm{NO}_{3}{ }^{-}-\mathrm{N}_{\text {eff }}(\square)$. C) Evolution of the feret diameter (mm) and breakage episodes indicated with dotted arrows. D) Stereomicroscopy image of the granules on day 339 with the scale bar indicating $2 \mathrm{~mm}$. 
Figure 3S
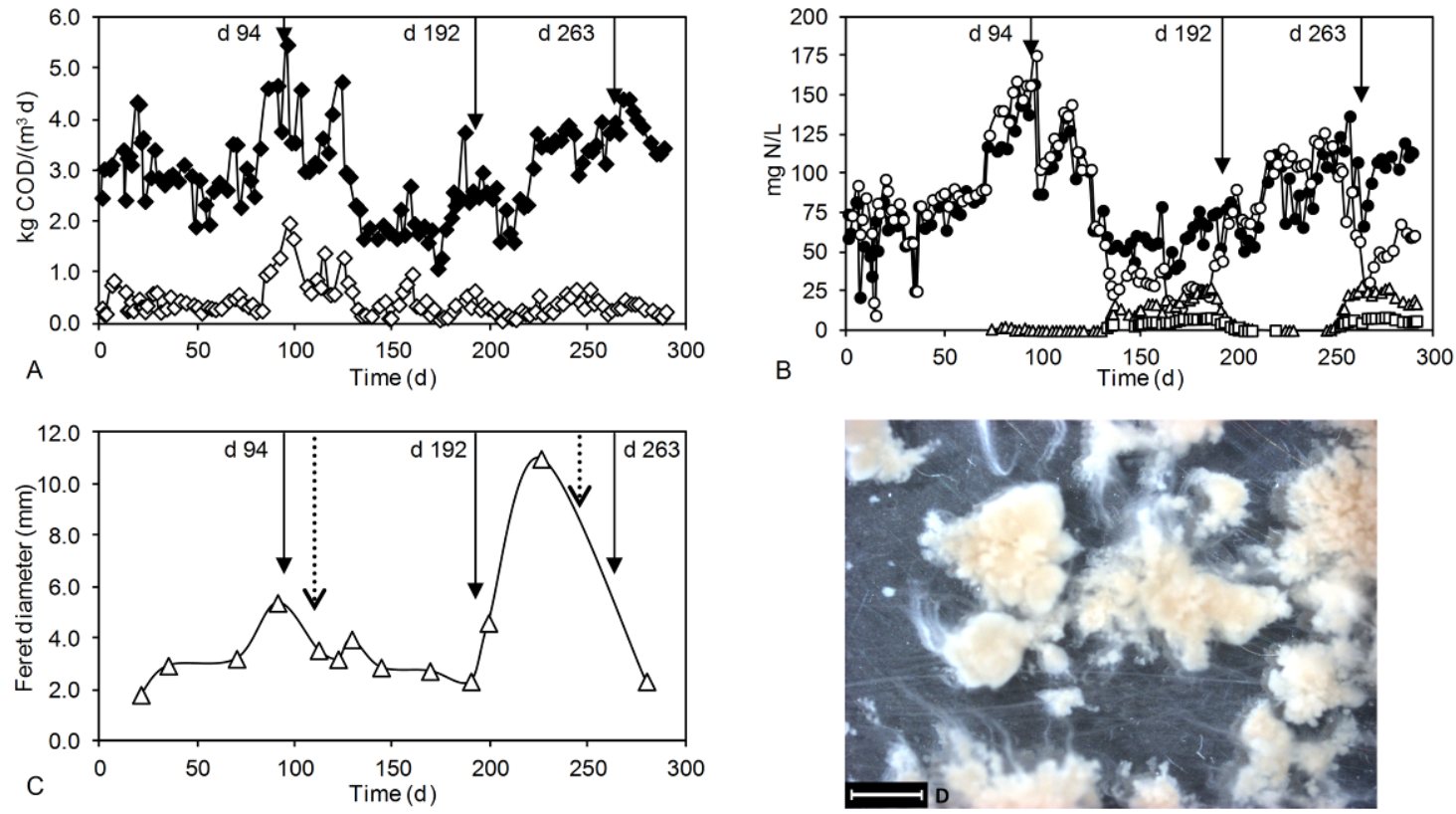

Figure 3S. Operational performance of $\mathrm{R} 3$ fed with processing marined products effluent and sampling dates (days 94, 192 and 263) indicated with arrows. A) Organic loading rate $\left(\mathrm{kg} \mathrm{COD} /\left(\mathrm{m}^{3} \mathrm{~d}\right)\right)$ in the influent $\left(\mathrm{OLR}_{\mathrm{inf}}, \diamond\right)$ and in the effluent $\left(\mathrm{OLR}_{\mathrm{eff}}, \diamond\right)$; B) nitrogen compounds concentrations (mg N/L): $\mathrm{NH}_{4}{ }^{+}-\mathrm{N}_{\text {inf }}(\bullet), \mathrm{NH}_{4}{ }^{+}-\mathrm{N}_{\text {eff }}(\bigcirc), \mathrm{NO}_{2}-\mathrm{N}_{\text {eff }}(\triangle)$ and $\mathrm{NO}_{3}{ }^{-}-\mathrm{N}_{\text {eff }}(\square)$ in the reactor. C) Evolution of the feret diameter $(\mathrm{mm})$ and breakage episodes indicated with dotted arrows. D) Stereomicroscopy image of the granules on day 263 with the scale bar indicating $2 \mathrm{~mm}$. 
Table 1S. List of 16S and 23S rRNA targeted oligonucleotide probes used for in situ identification of microorganisms, formamide percentages $(\% \mathrm{~F})$ and target organisms. Last column indicates if positive $(\checkmark)$ or negative $(\mathbf{x})$ results were obtained after its application.

\begin{tabular}{|c|c|c|c|c|}
\hline Probe & Probe sequence $\left(5^{\prime} \rightarrow 3^{\prime}\right)$ & $\% \mathrm{~F}$ & Target organisms & Results \\
\hline EUB338I ${ }^{\mathrm{a}}$ & GCTGCCTCCCGTAGGAGT & $0-50$ & Bacteria domain & \multirow{3}{*}{$\checkmark$} \\
\hline EUB338II $^{\mathrm{a}}$ & GCAGCCACCCGTAGGTGT & $0-50$ & Planctomycetales & \\
\hline EUB338III $^{\mathrm{a}}$ & GCTGCCACCCGTAGGTGT & $0-50$ & Verrucomicrobiales & \\
\hline$\overline{\text { ALF1B }}$ & CGTTCGYTCTGAGCCAG & 20 & Alphaproteobacteria & $\checkmark$ \\
\hline NOLI644 & TCCGGTCTCCAGCCACA & 35 & Candidatus Alysiosphaera europaea & $x$ \\
\hline$\overline{\mathrm{PPX} 3}$ & TGGCCCACCGGCTTCGGG & 50 & Candidatus Alysiomicrobium bavaricum & $x$ \\
\hline DF198 & ATCCCAGGGCAACATAGTCT & 35 & Candidatus Monilibacter batavus & $x$ \\
\hline COMBO1031 & CACCTGCAGTGGCCTCCCGA & 35 & Candidatus Combothrix italica & $x$ \\
\hline MEG983b $^{\mathrm{b}}$ & CGGGATGTCAAAAGGTGG & 35 & Meganema perideroedes & $\checkmark$ \\
\hline MEG1028 & CTGTCACCGAGTCCCTTGC & 35 & Meganema perideroedes & $\checkmark$ \\
\hline BET42a* & GCCTTCCCACTTCGTTT & \multirow{2}{*}{35} & \multirow{2}{*}{ Betaproteobacteria } & \multirow[t]{2}{*}{$\checkmark$} \\
\hline Competitor & GCCTTCCCACATCGTTT & & & \\
\hline CURVI997* & CTCTGGTAACTTCCGTAC & \multirow{3}{*}{35} & \multirow{3}{*}{$\begin{array}{c}\text { Curvibacter delicatum ATCC14667; } \\
\text { Pseudomonas lanceolata AB021390 and } \\
\text { few more Betaproteobacteria }\end{array}$} & \multirow[t]{3}{*}{$x$} \\
\hline Competitor1 & CTCTGGCAACTTCCGTAC & & & \\
\hline Competitor2 & CTCTGGTCACTTCCGTAC & & & \\
\hline LDI & CTCTGCCGCACTCCAGCT & 35 & Leptothrix discophora & $x$ \\
\hline$\overline{\text { SNA }}$ & CATCCCCCTCTACCGTAC & 45 & Sphaerotilus natans & $\checkmark$ \\
\hline GAM42a* & GCCTTCCCACATCGTTT & \multirow{2}{*}{35} & \multirow{2}{*}{ Gammaproteobacteria } & \multirow[t]{2}{*}{$\checkmark$} \\
\hline Competitor & GCCTTCCCACTTCGTTT & & & \\
\hline G123T* & CCTTCCGATCTCTATGCA & \multirow{2}{*}{40} & \multirow{2}{*}{$\begin{array}{l}\text { Thiothrix eikelboomii, T. nivea, T. unzii, } T . \\
\quad \text { fructosivorans, } T \text {. Defluvii }\end{array}$} & \multirow[t]{2}{*}{$\checkmark$} \\
\hline Competitor & CCTTCCGATCTCTACGCA & & & \\
\hline CFX1223 & CCATTGTAGCGTGTGTGTMG & 35 & phylum Chloroflexi & $\checkmark$ \\
\hline GNSB941 & AAACCACACGCTCCGCT & 35 & phylum Chloroflexi & $\checkmark$ \\
\hline EUK516 & ACCAGACTTGCCCTCC & 25 & Eukarya & $\checkmark$ \\
\hline MY1574 & TCCTCGTTGAAGAGC & 20 & Eumycota (Fungi) & $\checkmark$ \\
\hline
\end{tabular}

${ }^{\mathrm{a}} \mathrm{EUB} 338_{\text {mix }}$ probe is an equimolar mixture of probes EUB338I, EUB338II and EUB338III.

${ }^{\mathrm{b}} \mathrm{MEG}_{\text {mix }}$ probe is an equimolar mixture of probes MEG983 and MEG1028.

*Probes that were used in a 1:1 ratio together with their specific probe competitors. 